\title{
Social Exchange and Micro Social Order
}

Edward J. Lawler

Cornell University

Shane R. Thye

University of South Carolina

Jeongkoo Yoon

Ewha Womans University

American Sociological Review (2008), 73, 519-542.

The order of authorship is random and does not reflect differential contributions. Direct correspondence to Edward J. Lawler, Department of Organizational Behavior, School of Industrial and Labor Relations, Cornell University, Ithaca, NY 14853 (ejl3@cornell.edu). This research was supported by a collaborative National Science Foundation grant (SBR-9614860) to Cornell University and the University of South Carolina. An earlier version of this article was presented at the 2006 Annual Meetings of the American Sociological Association. The authors thank Marty Kuhn for designing the computer program and Jenny Craig, Lisa Dilks, Lena Hipp, Elizabeth Mattern, Tucker McGrimmon, Jennifer Triplett, and Emily Arnold for help with the experiments. Shelley Correll and Frank Flynn provided helpful comments on an earlier draft. 


\begin{abstract}
This study uses an affect theory of social exchange (Lawler 2001) to investigate how and when network structures generate "micro social orders.” Micro social order entails recurrent interactions, emotional reactions, perceptions of a group, and affective sentiments. The core theoretical argument is that micro orders, involving behavioral, cognitive, and affective dimensions, develop and are stronger to the degree that (1) actors engage in highly joint tasks or activities and (2) these tasks generate a sense of shared responsibility for the interaction outcomes. A laboratory experiment varies different forms of social exchange-negotiated, reciprocal, generalized, and productive — within a network structure, and offers strong support for the core expectation that productive forms of exchange generate the strongest micro order. Conversely, generalized exchange generates the weakest order, with negotiated and reciprocal forms in between. In general, productive exchange bolsters more exchange behavior, more positive feelings, perceptions of cohesion at the network level, and affective attachments to the network as a social unit. This research has broad implications for the conditions under which task activity promotes micro social orders that involve strong person-to-group ties (as opposed to person-to-person ties) and affective sentiments regarding the social unit.
\end{abstract}


It is generally understood that social structures pattern and shape social interaction and also that social interactions can generate, reproduce, and sometimes alter social structures (e.g., Emerson 1981; Giddens 1984; Stryker 1980; Turner 1978). When structures promote repeated interactions among the same individuals, people tend to form enduring relations or group affiliations (e.g., Emerson 1972a, 1972b; Homans 1950). If enduring relations or affiliations form, the social units that frame or make possible these relations—small groups, organizations, or communities — may become objects or realities for actors (Berger and Luckmann 1967). It is plausible that people develop ties to social units, as they interact with each other, and that these ties are a separable, independent force, distinct from the ties people have to each other (e.g., see Mead 1934; Parsons 1951; Tajfel and Turner 1986). In this article, we ask how and when social exchange processes generate per- son-to-unit ties that reflect micro social order. The affect theory of social exchange (Lawler 2001) guides our theoretical and empirical analysis.

The distinction between person-to-person and person-to-social unit ties has broadreaching implications for micro social order. Individuals may be bound to each other primarily by their interpersonal ties (e.g., friends, associates, or colleagues) or they may be conjoined primarily by some common tie to a social unit (e.g., its mission, values, or identity-affirming features). Parsons (1951) argues that theorizing the problem of social order involves an analysis of person-to-person and person-to-society ties as analytically distinct phenomena, a view traced to Durkheim ([1893] 1997). This distinction is also evident in Giddens’s (1984) structuration theory, Collins’s (2004) theory of interaction ritual chains, and contemporary theories of economy and society (Swedberg 2003). Moreover, the two kinds of ties thematically appear in theories of collective action (Benford and Snow 2000; Brewer and Gardner 1996; Prentice, Miller, and Lightdale 1994), embeddedness in economic transactions (Granovetter 1985, 1992; 
Uzzi and Lancaster 2004), and structural cohesiveness and equivalence (Burt 1978; Moody and White 2003). In more general terms, person-to-unit ties are one aspect of the classic self/collectivity or individual/society dichotomy that has historically framed sociological theories of order.

We approach the problem of social order in this article from a social exchange perspective (see Cook and Emerson 1978; Ekeh 1974; Homans 1950; Lawler, Thye, and Yoon 2000; Molm 2003a). Our analysis begins with an exchange network, defined as a set of possible or potential ties that limit and constrain who may exchange and interact with whom. A social exchange occurs when two actors give something of value to one another and receive something of value in return (Emerson 1972a, 1972b; Wilier and Anderson 1981). The outcome of interest is the micro social order that emerges from the patterns of interaction or exchange produced by the network. Micro social orders can be construed as emergent social units with group-like properties (e.g., see Lawler 2002; Lawler and Thye 1999); they can transform a network, crosscut groups or organizations, or be subdivisions within a larger social structure. The concept of a micro social order is implicit in theorizing that falls under the broad umbrella of “microsociology” (Scheff 1990; Stolte, Fine, and Cook 2001). Our purpose here is to theorize and empirically examine how and when micro social order develops among a set of actors who have structural ties to one another.

We define a micro social order as a recurrent or repetitive pattern of activity (interaction, transaction, exchange) among two or more actors with four attendant dimensions: (1) actors exchange with or orient their behavior toward members of the social unit, (2) they experience global emotions from those interactions, (3) actors come to perceive they are a social unit, and (4) over time, individuals develop affective attachments to the larger social unit (Lawler 2002). 
This concept of micro order interweaves collectively-oriented behavior (i.e., interactions with members or the group), positive affect (i.e., global emotions and affective attachments to the unit), and group perceptions (i.e., a sense of unity or cohesion). In these terms, a network becomes a micro social order to the degree that it generates recurrent patterns of exchange, a sense of network cohesion, and positive feelings directed at the actors and the overarching network. Together, these behavioral, emotional, and cognitive conditions imply that actors define themselves with reference to a larger social unit and are willing to act on its behalf. Micro social orders involve the development of a self-to- collectivity relationship.

The affect theory of social exchange (Lawler 2001) indicates that the structure of social exchange bears on the degree that micro social orders are likely to emerge from exchange processes. One important structural dimension is the connection between the giving behaviors in the transaction. Business or economic transactions tend to be contractual, negotiated, and explicit; the giving behaviors are closely connected and tit-for-tat. Exchanges in friendship relations tend to be implicit and occur over unspecified time periods; they lack the explicit, titfor-tat character of business transactions. Collective action involves person-to-collective transactions wherein a jointly-produced good generates benefits for those who contribute to its production. Public goods dilemmas and informal employer-employee contracts tend to fit this pattern. Finally, the structural connections between giving behaviors may allow actors to only give and receive from different others within a larger group or social structure (Bearman 1997; Malinowski 1922). Social exchange theorists have conceptualized these exchange structures as four forms of exchange referred to, respectively, as negotiated, reciprocal, productive, and generalized (Ekeh 1974; Emerson 1981; Lawler 2001; Molm 1994). Our theory hypothesizes that these forms of exchange differ in their capacity to produce micro social order. 
Beyond social exchange theory there are a wide range of approaches that address some version of the stability and micro social order problem. Rational choice theories emphasize the role of monitoring, norms, and sanctions to redress the tension between individual and collective interests (Coleman 1990; Hechter 1987; Nee and Ingram 1998). Norms and sanctions emerge because of “externalities” produced by the widespread pursuit of individual self interest. Social constructionist theories stress the consensual meanings and interpretations that emerge endogenously among actors who engage in regular or repeated interactions (Berger and Luckmann 1967; Goffman 1959). Such meanings can “objectify” relations or groups, making them "realities" for actors. Identity theories emphasize how social interactions create and sustain shared self-other definitions associated with structural roles, social categories, and group affiliations (Burke 1991; Hogg 2004; Stryker 1980). Social exchange theories emphasize the role of trust and commitment in stabilizing relations (Cook, Hardin, and Levi 2005; Kollock 1994; Molm 2003a, 2003b). Although rational choice, social constructionist, identity, and social exchange theories approach the self-collectivity relationship in varied ways, they have overlapping and convergent themes. The affect theory of social exchange (Lawler 2001) interweaves elements from each approach to incorporate an actor who experiences emotion or affect from exchange.

Emotions are generally defined as positive or negative evaluative states with physiological, neurological, and cognitive features (Damasio 1999; Izard 1991; Kemper 1978). Our theorizing draws from work in psychology, sociology, and neuroscience. From psychology, emotions entail both a response to a stimulus (e.g., exchange with another) and a stimulus that itself produces cognitive work (Clore, Schwarz, and Conway 1994; Izard 1991). From sociology, cognitive work involves interpreting the meaning of emotions felt in the context of relationships, 
situational norms, and self-other definitions (see Hochschild 1979; Kemper 1978; Smith-Lovin and Heise 1988; Thoits 1989). From neurobiology (Damasio 1999; LeDoux 1996), emotions induce organism-wide neurological effects that generate a rudimentary awareness of a selfcollectivity connection. ${ }^{1}$ Drawing on these literatures, everyday feelings from repeated interactions may foster the development of sentiments (positive or negative) about a social unit, and it is important to understand the conditions under which this is likely to occur.

\section{BACKGROUND: RELATIONAL DIMENSIONS OF EXCHANGE}

Social exchange theories conceive of relationships in purely instrumental and transactional terms. A basic tenet of social exchange theory is that individuals form and maintain a relationship as long as the benefits from that relationship exceed those available elsewhere (Emerson 1972a, 1972b; Molm and Cook 1995; Wilier 1999). By implication, better offers or greater individual profits from alternatives break apart existing relations. This tenet is one reason that issues of power, reward allocation, and distributive justice have been central to the exchange-theoretic landscape. The exchange- network tradition, in particular, has focused on how network structures produce power gradients and stratification when the payoffs from exchange benefit some individuals at the expense of others (Cook et al. 1983; Emerson 1972a,

\footnotetext{
${ }^{1}$ The organism-wide neurological effects mean that when an actor feels good he feels good all over; when an actor feels bad he feels bad all over. These effects are due to chemical secretions - such as dopamine, epinephrine, and oxytocin - that stem from different regions of the brain. Damasio (1999, 2001) indicates that these neurological secretions generate the "feeling of feelings" and suggests these are the foundation for consciousness, that is, a sense of the self juxtaposed to the external objects or events. For such reasons, neurological processes may promote awareness of or attention to social unit affiliations that are part of the context within which emotions occur.
} 
1972b; Markovsky, Wilier, and Patton 1988; Skvoretz and Lovaglia 1995; Stolte and Emerson 1977; Thye 2000a; Thye, Lovaglia, and Markovsky 1997; Wilier 1999). The relational aspect of social exchange is tied to the fact that structures tend to generate repeated exchanges among the same actors. Emerson (1972b) portrays this as a key difference between social and economic exchange.

There are two general approaches to the relational aspect of social exchange. Emerson (1972b, see also Homans 1961) adopts an “individualistic” approach whereas Ekeh (1974; see also Malinowski 1922; Levi-Strauss 1969) offers a “collectivist” viewpoint. The individualistic approach starts with actors in a simple network structure who have rational-choice or behavioral incentives to exchange. Few, if any, assumptions are made about a larger group or social unit. Here, micro orders are emergent and necessarily tenuous as they are tied to individual self interest. Relations develop and prevail only to the degree that the incentives to exchange, preferences of actors, and structures of opportunity are stable. Relations as such emerge out of individualist conditions. In contrast, the collectivist approach assumes a larger social unit or group affiliation. Social exchanges as such are embedded within and reflect a cultural or normative order or framework (see Bearman 1997; Ekeh 1974). Here exchange takes on a more symbolic or expressive character and is driven by the cultural beliefs or norms of the larger social unit. In sum, the individualistic perspective draws attention to the exchange processes through which micro orders develop and are sustained, while the collectivist account emphasizes how exogenous conditions—structural or cultural—promote cooperation and minimize opportunism (see also Fukuyama 1995).

The affect theory of social exchange (Lawler 2001) further develops and bridges the individualist and collective approaches. It starts with and assumes an individualistic context but 
then shows how actors develop a collective affiliation and affective ties. Our approach differs from other social exchange approaches in several ways (for reviews, see Lawler and Thye 2006; Thye, Yoon, and Lawler 2002). First, we argue that in social exchange there are social constructionist and identity processes that alter the foundation of relationships and groups, essentially transforming them from transactional (instrumental) to relational (expressive) entities. Second, we assert that this transformation is most likely when structures lead the same actors to interact or exchange repeatedly over time, a condition that is generally assumed in much of social exchange theory (Emerson 1981; Wilier 1999). Third, the mechanism through which this occurs is emotional or affective. We posit, and have found empirically, that solving an exchange problem is an accomplishment that produces positive emotions (see Lawler et al. 2000; Lawler and Yoon 1996); and under some conditions, actors associate these emotions with their relational or group affiliation (Lawler and Yoon 1996, 1998; Lawler et al. 2000).

The relational consequences of repeated exchanges are most thoroughly documented in research on commitment in exchange relations (e.g., Kollock 1994). Commitment is generally defined as the tendency of actors to stay with and continue to exchange with those they have exchanged with in the past (Kollock 1994; Lawler and Yoon 1996; Molm, Takahashi, and Peterson 2000). Research reveals greater rates of commitment when actors face high uncertainty or risk (Kollock 1994; Molm, Peterson, and Takahashi 1999) and also when they have equal power or high mutual power and dependence (Lawler and Yoon 1996). There are two analytically-distinct interpretations for the emergence of commitment in social exchange: trust and affect. The trust interpretation asserts that individuals develop stable, ongoing relations in response to high risk and uncertainty (see Cook 2005; Kollock 1994; Molm 1994, 2003a). From this perspective, commitment is a strategy to reduce uncertainty in an unstable environment and 
trust is the "glue" that binds together relations and groups (see also Fukuyama 1995; Yamagishi and Yamagishi 1994). The affect explanation contends that actors develop more stable, cohesive relations and groups if and when exchanges generate positive feelings that actors associate with the social unit (i.e., relation or group). Recent evidence suggests that uncertainty reduction and affect are "dual processes” that operate in parallel to promote stable, cohesive, ongoing exchange relations (see Lawler et al. 2000; Yoon and Thye 2000). We focus here on the role of affect.

The theory of relational cohesion (Lawler and Yoon 1996) was the first to draw attention to the role of affect in social exchange (see also Lawler and Thye 1999). The central argument is that relations with more equal power-dependence and greater mutual dependence produce more frequent exchange between pairs of actors in a network and this leads to relational commitments. These effects are indirect and operate through an endogenous causal chain: (1) more frequent exchange generates more positive feelings; (2) more positive feelings generate a perception of the exchange relation as a unifying (cohesive) force; and (3) greater perceived cohesion promotes commitment behavior (see Lawler and Yoon 1996,1998). Research has consistently supported this exchange-to- emotion-to-cohesion chain and also affirmed that power dependence effects on relational commitments occur indirectly, through this process (Lawler and Yoon 1993, 1996, 1998; Lawler, Thye, and Yoon 2000, 2006). The affect theory of social exchange (Lawler 2001, 2002, 2006) addresses questions and issues that are complementary to relational cohesion theory, focusing not on conditions of power, but on determinants of social order across the forms of exchange. One question examined in the current research is whether the relational-cohesion process mediates the effects of forms of exchange on micro social orders. 
Insert Table 1

\section{THE AFFECT THEORY OF SOCIAL EXCHANGE}

The affect theory of social exchange posits that the task jointness of the exchange or activity determines whether actors perceive the social unit as a source of their individual emotions or feelings. Actors attribute their individually-felt emotions to their relations or groups if the task is high in jointness; whereas if the task is low in jointness they attribute the emotions to their own or another's behavior. Jointness varies along both objective and subjective dimensions. For example, a manager may objectively structure the tasks of a work group to be highly interwoven. The jointness of other tasks may depend less on objective conditions and more on the subjective framing of the task. To illustrate, consider childrearing by two parents or partners. If parental responsibilities are subjectively defined to be loose and overlapping, rather than divided precisely, "parenting” should foster a greater sense of joint responsibility. The key point is that both objective and subjective conditions are important.

The theory makes a sharp distinction between global emotions that are immediately felt and specific emotions that emerge from subsequent interpretations of global emotions or feelings. This distinction is based primarily on Weiner's (1986) attribution theory of emotion, but it also dovetails with Damasio’s (1999) notion that "feeling feelings" make salient that one is being affected in some way. Global emotions are involuntarily felt as a result of exchange or other social interaction. Feeling up/down, good/bad, or pleasure/displeasure are common examples. Specific emotions are associated with, or directed at, particular social objects such as self, other, or a social unit. Examples include pride in self and gratitude toward the other, shame 
in self and anger toward the other, and affective attachments or detachments from a social unit. In the theory, the specific emotions directed at self, other, or a social unit emerge as actors experience and interpret the sources of their global feelings. The theory’s conceptual framework for these emotions is provided in Table 1.

Theory and research in psychology indicates that people tend to attribute positive events (success) to themselves and negative events (failures) to others or the situation (Jones and Davis 1965; Kelley 1967; Mezulis et al. 2004). The implication is that individuals, even those engaged in a joint task, will be more inclined to attribute group success to their own efforts and feel greater pride in self rather than gratitude toward the other. In the case of task failure, the predominant emotion would be anger toward one or more others rather than shame toward one’s self. These self-serving attributions suggest that it is difficult for repeated exchanges to generate positive sentiments about relations or groups. The affect theory of social exchange takes this as a challenge and specifies conditions under which social-unit attributions of emotion will overcome or mitigate self-serving biases to produce person-to-unit attachments.

Specifically, the theory asserts there are structural (objective) and cognitive (subjective) conditions that determine when global emotions are attributed to social units. The primary structural condition is the degree that each individual's contributions to task success (or failure) are separable (distinguishable) or nonseparable (indistinguishable). This comparison is informed by Williamson’s (1985) trenchant analysis of work conditions and governance structures. He argues that relational-team governance structures are common where work structures make it difficult to distinguish individual contributions, thus generating a sense of collective responsibility. One implication is that specialized or independent roles in a work setting make salient individual responsibility; whereas collaborative or overlapping roles make salient shared 
or collective responsibility. For our purposes, this implies that structures of collective responsibility yield greater coordination or, in our terms, successful social exchange. Adopting these notions from Williamson (1985), the affect theory characterizes the objective structural condition as the nonseparability of task behaviors and contributions.

The subjective dimension of jointness is the degree that the exchange task promotes a sense of shared responsibility for success or failure at exchange. If social exchange generates a sense of shared responsibility, actors are more likely to interpret their individual feelings as jointly produced in concert with others and thus attribute those feelings to social units. To illustrate, if employees in a work team perceive a shared responsibility for team success, positive feelings from doing the task are more likely to generate affective attachments to the team. On the other hand, if members share in the responsibility for team failure, the resulting negative feelings are likely to generate affective detachments from the group. Given this logic, there are two core propositions of the theory (Lawler 2001):

Proposition 1: The greater the nonseparability of task activities and outcomes, the greater the perception of shared responsibility.

Proposition 2: The greater the perception of shared responsibility for success or failure at a joint task, the more inclined actors are to attribute the global emotions to social units (relations, networks, or groups).

These propositions constitute a causal chain wherein nonseparability of task activity generates perceived shared responsibility and, in turn, shared responsibility produces social unit attributions of emotions (i.e., affective attachments). A theoretical link can be drawn between 
this causal sequence and that of relational cohesion theory. These two theories specify parallel yet interrelated processes. Whereas the affect theory theorizes the consequences of task nonseperability, the theory of relational cohesion theorizes the effects of total and relative power in the relation. All these factors capture and reflect types of interdependence that should yield greater exchange frequency. Nonseparability, as Williamson implies, involves more task interdependence, which enhances task coordination, reduces the cost of monitoring others, and yields a heightened sense of collective responsibility. High total and equal relative power, as documented in relational cohesion theory, entail greater outcome interdependence, which directly promotes concession making due to the profits at stake. Taken together, the overall implication is that task nonseperability should generate perceptions of shared responsibility and also activate the relational cohesion process linking exchange frequency- to-emotion-tocohesion. In this article, we empirically examine the link between the two theories by testing whether the relational- cohesion process mediates the effects of forms of exchange on affective attachments to the unit.

To conclude, the strongest affective ties to the social unit occur when the structure of exchange entails high nonseparability and fosters a high sense of shared responsibility. Theoretically, these propositions are applicable to any structural condition that generates variation in the objective (nonseparability) or subjective (shared responsibility) conditions. We next apply these principles to the four forms of social exchange illustrated in Figure 1. 
Productive exchange involves a jointly-produced collective good wherein people unilaterally provide benefits to the group and receive benefit from it. Interdependence is high, yet there are coordination problems that need to be solved to generate the common good and allocate collective benefits. This implies an "assurance game" in which the largest payoffs are from mutual cooperation (Kollock 1998). Prototypes include a business partnership, coauthoring scholars, or a homeowners' association working together to solve a community problem. In each case, individual agents cannot accomplish the desired outcome alone but stand to reap significant benefits from cooperation. Actors make individual contributions but these are interwoven in the joint products of their behavior. The affect theory asserts that nonseparability and perceptions of shared responsibility should be higher here than in other forms of exchange. The tendency to attribute emotions to the social unit (the network or group) should also be strongest in a productive exchange environment.

Direct exchange occurs when two or more actors give directly to one another over time. There are two forms: negotiated and reciprocal. Negotiated exchange involves bargaining over the terms of an agreement. Through this process, actors develop a contractual agreement that allows them to provide benefits to one another (e.g., a salary for work or a price for a product). Agreements emerge from a process that entails offers, counteroffers, and mutual concessions. Actors' contributions to exchange- their offers and concessions-are distinguishable, but there is a joint result produced by the explicit agreement on terms of the trade. The jointness of the exchange should be salient in negotiated exchange, and the sense of shared responsibility for the result should be relatively high, though lower than that found in productive exchange. Thus, nonseparability and shared responsibility should result in global emotions being attributed in part to the social unit, but somewhat attenuated relative to productive exchange. 
Reciprocal exchange is similar to negotiated exchange, except that giving and receiving are sequential, unilateral acts separated by time and provided without explicit expectations of reciprocity. Patterns of reciprocity can emerge over time, however, if actors make their giving contingent on the prior giving by the other (see Molm et al. 1999). If A receives a unilateral benefit from B, A may feel obligated to provide benefits in return to B; and if A gives unilateral benefits to B, A may come to expect that B will later reciprocate (Gouldner 1960). Giving advice to a fellow employee, providing favors to a roommate, and inviting colleagues to dinner are acts that may initiate or become part of reciprocal exchanges. A major issue for actors in reciprocal exchange is risk or trust, that is, whether actors anticipate or expect reciprocal cooperative behavior from others (Molm 2003a, 2003b). Given that each act of giving is distinct, however, the jointness of exchange is not as explicit or salient as in productive or negotiated exchange. The degree of nonseparability and sense of shared responsibility, therefore, should be lower here.

Generalized exchange is an indirect form of exchange that entails three or more actors who can give to (and receive from) one other, but here, givers and receivers are not matched in pairs. In an organization, a structure of generalized reciprocity among different departments exists if a department provides information to one other department but receives information from a different department. Other common examples involve acts of generalized reciprocity such as helping a stranded motorist or opening a door for a stranger. Like productive exchange, a structure of generalized exchange fosters high levels of interdependence and makes coordination a significant problem. Unlike productive exchange, giving behaviors are highly separable; and, all things being equal, acts of giving benefit are unlikely to generate much sense of shared 
responsibility. Thus, based on the affect theory, generalized exchange poses important obstacles to micro social order. ${ }^{2}$

To conclude, applying core propositions of the theory produces four general predictions for forms of exchange, as follows:

Hypothesis 1: Productive exchange generates stronger perceptions of shared responsibility and stronger global emotions than do direct or generalized exchange.

Hypothesis 2: Direct exchange produces stronger perceptions of shared responsibility and stronger global emotions than does generalized exchange.

Hypothesis 3: Within direct forms of exchange, negotiated exchange produces stronger perceptions of shared responsibility and stronger global emotions than does reciprocal exchange.

Hypothesis 4: The strength of a micro social order is ordered as follows across forms of social exchange: productive $>$ [negotiated $>$ reciprocal] $>$ generalized.

Hypothesis 4 has a number of subcomponents that correspond to the four dimensions of micro social order. It predicts the ordering of (1) frequency of exchange, (2) global positive feelings about the exchanges, (3) perceptions of network cohesion, and (4) affective attachments

\footnotetext{
${ }^{2}$ Ekeh (1974) categorizes what we term productive and generalized under the same rubric (generalized) on the grounds that these are both collective forms involving high interdependence (see also Yamagishi and Cook 1993). While we acknowledge and accept Ekeh's (1974) observation, the affect theory of social exchange suggests that different degrees of shared responsibility render these qualitatively different.
} 
about the social unit across the four forms of exchange. The experiment to follow tests the impact of the forms of exchange on these dimensions of micro order.

Other theoretical traditions predict different orderings among some of the forms of social exchange based on issues of risk, the expressive value of reciprocity, and trust (Ekeh 1974; Molm 2003a, 2003b). Molm and colleagues (2003a, 2003b; Molm, Collett, and Schaefer 2007) predict and demonstrate empirically that reciprocal exchange fosters more commitment and stronger positive feelings about exchange partners (Molm et al. 1999; Molm et al. 2000) than does negotiated exchange. This suggests the opposite ordering for negotiated and reciprocal exchange (Hypothesis 3). Molm and colleagues also theorize that reciprocal exchange involves greater risk of nonreciprocity and more expressive value than negotiated exchange due to the latter’s explicit, binding character. As a result, giving behavior in reciprocal exchange is interpreted more positively by partners than giving in negotiated exchanges. Molm’s logic further suggests that because generalized exchange involves indirect, rather than direct, reciprocity, it generates the highest levels of expressive value (Molm et al. 2007). As such, she predicts that generalized exchange will produce even stronger positive feelings and commitments than both negotiated and reciprocal exchange (see Molm 2003a). The collectivist approach of Ekeh (1974) and the individualist approach of Molm (2003a, 2003b) both theorize that trust is higher in generalized than in direct exchange. Our research considers these alternatives in the context of the first simultaneous examination of all four forms of exchange identified in the exchange tradition. ${ }^{3}$

\footnotetext{
${ }^{3}$ We do not claim a competitive test vis-a-vis the formulations of Ekeh (1974) or Molm (2003a). This study is designed to test implications of the shared- responsibility logic of the affect theory, examining micro social order across all four forms of exchange simultaneously. We assume somewhat different initial conditions (i.e., exchange partners need not exclude connected others)
} 


\section{Specific Emotions Toward Self and Other}

Based on Propositions 1 and 2, objective task jointness and the sense of shared responsibility determine whether social-unit or self-serving attributions are likely to emerge. This has implications for specific emotions directed at self and others. To the degree that individuals engage in social-unit rather than self-serving attributions, they should feel both pride in self and gratitude toward the other, following successful social exchange. That is, gratitude toward the other does not reduce the sense of pride in self, or vice versa. By comparison, if actors engage in self-serving attributions, they attribute positive results to their own efforts and pride toward self and gratitude toward others will thus be inversely related. Therefore, the forms of social exchange that promote stronger micro social orders should also generate more pride and more gratitude.

The case of negative emotions is more complex. On one hand, as with positive emotions, when individuals fail to exchange and engage in social-unit attributions both anger (toward the other) and shame (toward the self) should be mitigated as the focus is on the social unit. Given the theory, this would lead us to conclude that negative emotions will be less likely to emerge within forms of exchange high on objective task jointness. On the other hand, if individuals engage in self-serving attributions, failures to exchange should generate anger toward the other but not shame toward the self. This would suggest that the mean level of anger will be greater than the mean level of shame. Overall, the theory suggests that the forms of exchange should reveal the following order for the specific emotions directed at self and other:

relative to these authors, and as such, we see our approach and those of Ekeh (1974) and Molm (2003a) as complementary. We return to these differences in the discussion section. 
Hypothesis 5: The ordering of positive emotions directed at self (pride) and other (gratitude) across the forms of exchange should correspond with the ordering of objective task jointness: productive $>$ [negotiated $>$ reciprocal] $>$ generalized.

Hypothesis 6: The ordering of negative emotions directed at self (shame) and other (anger) across the forms of exchange should be the inverse of the ordering of objective task jointness: generalized $>$ [reciprocal $>$ negotiated] $>$ productive.

\section{Mediating Processes}

The linkages between structure, interaction, and outcome are defining characteristics of exchange theories. A key issue is whether structures have direct or indirect effects on outcomes. Whereas Emerson (1972a, 1972b) and others (Wilier 1999; Markovsky et al. 1988) emphasize the direct effects of structure on outcomes, recent work reveals a shift in emphasis toward the mediating effects for structure. This is most clearly shown in research on commitment (Kollock 1994; Lawler and Yoon 1996; Molm et al. 1999) that emphasizes the mediating roles of uncertainty reduction, trust, risk, and affect. Emotional mediation is central to the theory of relational cohesion, given its focus on the indirect effects of structural power on relational commitments through this causal chain: exchange frequency $\rightarrow$ positive emotions $\rightarrow$ cohesion (Lawler and Yoon 1996; Thye et al. 2002). We propose that objective task nonseperability unleashes the endogenous process of relational cohesion theory, thereby strengthening affective attachments to social units. This is based on the supposition that objective task jointness promotes more frequent exchange by promoting coordination and a sense of collective responsibility. In turn, frequent exchange fosters more global positive feelings about the 
exchange tasks, as well as a greater sense of cohesion at the network level. Cohesion at the network level makes the network itself a relevant social object and possible target for affective sentiments. Thus, as a complement to Hypotheses 1 to 4, we test whether the endogenous relational-cohesion process mediates the impact of forms of social exchange on affective attachments, as follows:

Hypothesis 7: The effects of forms of exchange on affective attachments are mediated by the exchange-to-emotion-to-cohesion process, specified by relational-cohesion theory.

To summarize, this article conducts the first explicit test of the affect theory of social exchange (Lawler 2001) simultaneously comparing the four forms of social exchange identified by exchange theorists (Ekeh 1974; Emerson 1972b; Lawler 2001; Molm 1994). In basic terms, the theory identifies structural (task nonseparability) and cognitive (perceptions of shared responsibility) dimensions under which social exchange generates emergent micro social orders at the collective or group level. Applied to the forms of exchange, the theory predicts that productive exchange will generate the strongest micro orders and generalized exchange the weakest, while the two forms of direct exchange (negotiated and reciprocal) will fall in between. 


\section{METHOD}

\section{The Experimental Context}

The experiment, described below, created an interorganizational setting, in which three small, entrepreneurial firms have complementary strengths or niches and can reap benefits from an exchange of resources. Reflecting the four forms of social exchange, companies could explicitly divide profits from resources (negotiated); develop a pattern of giving resources to one another (reciprocal); partake in a joint-venture (productive); or give and receive from different actors (generalized). The setting was a three-actor, triadic network that varied only the form of exchange, as portrayed in Figure 1.

Triads are a simple and straightforward network configuration for examining the emergence of a micro social order (Simmel 1964). We designed the networks to capture a situation where: (1) actors have equal power because the network of opportunities for exchange does not give any of them a structural advantage, and (2) each actor can exchange with any or all of the other actors in the network to whom they are connected. That is, on any given episode each can exchange with none, one, or both of the others. ${ }^{4}$ The actors are therefore "free" to construct any set or pattern of relations, which may involve varied rates or types of exchange

\footnotetext{
${ }^{4}$ In the parlance of network exchange theory "null connections" are theoretically distinct from negative (exclusive) or positive (inclusive) connections (Brennan 1981; Wilier 1999). The vast majority of networks studied are negatively or exclusively connected (Molm and Cook 1995; Wilier 1999). Molm's theory and research examines negatively-connected networks (e.g., Molm 2003a, 2003b; Molm et al. 1999) and observes that the salience of conflict is greater in negotiated than reciprocal exchange. Our use of null connections lessens the salience of conflict across the forms of exchange because exclusion need not occur. We suggest that when conflict salience is reduced the theoretical process specified by Molm and colleagues (2007) will be attenuated.
} 
with their prospective partners. Such networks are well-suited to studying emergent social processes and are similar to many real-world contexts where actors can create and sustain a set of noncontingent relations. Another advantage is that these networks afford a very straightforward way to compare the four structural forms of social exchange. ${ }^{5}$

\section{Design and Procedures}

A total of 192 undergraduate students at a Northeastern and a Southeastern university participated in the experiment for payment. The experiment consisted of a four condition, completely randomized design that manipulated the four forms of social exchange. In all, 64 same- sex triads were randomly assigned to one of the four experimental conditions (16 triads per cell; 10 female and 6 male). Because data were collected at two universities, the experiment counterbalanced gender and university affiliation within each experimental condition.

Upon their arrival, subjects were randomly assigned to separate cubicles where they read written instructions. The instructions described the setting, which involved three small computer firms (Alpha, Beta, and Gamma) and indicated that each subject was the head of her respective company. Each was informed that the company specializes in the production of memory chips but lacks the technology to make microprocessors. Subjects were told they could acquire or receive such technology from the other companies. A diagram of the network was present in each subject room to show who could give valued resources to whom, thus subjects understood

\footnotetext{
${ }^{5}$ Simultaneously comparing all four forms of exchange is complex. For instance, it may be impossible to instantiate an exclusively connected generalized exchange in a triad. Our approach minimizes the ancillary or extraneous differences among the conditions in accord with the requirements of our theory.
} 
how each of the three participants could interact with the others. The instructions explained that there would be multiple “interaction episodes.” All interactions took place using desktop computers and subjects were anonymous.

In each episode, subjects decided whether to give resources to one or more others, and these choices were made simultaneously by the three subjects. Productive, reciprocal, and generalized exchange involved a single choice, that is, to give or not to give. In the reciprocal and generalized exchange conditions, the choice was whether to unilaterally give to another; while in the productive exchange condition the choice was whether to give to a joint venture. The negotiated exchange condition entailed up to three rounds of offers and counteroffers in an effort to divide a pool of profits. To account for the three rounds of negotiations and equate this condition with the others on the number of interaction opportunities, there were a third fewer episodes (16) in the negotiated condition relative to all others (48). ${ }^{6}$

All subjects were instructed to maximize the profits of their own companies and, in accord with related research (e.g., Lawler et al. 2000; Lawler and Yoon 1996), they had information only on their own profit points during the experiment. They received a running cumulative total of their own profits updated after each exchange opportunity or episode (see Molm et al. 1999). Subjects were informed that their pay for the study was based entirely on the profits they acquired for their companies, and at the conclusion of the session, the number of points earned were converted to cash using a standard formula.

\footnotetext{
${ }^{6}$ In all conditions there are 48 opportunities to interact (16 episodes X 3 rounds $=48$ in negotiated; 48 episodes $\mathrm{X} 1$ round otherwise). We chose this number of opportunities to ensure the study would generate reliable patterns of exchange, equate the four conditions in terms of time and number of observations in the statistical analysis, and maintain the involvement of the subjects. We used the results from a series of pretests at each university to guide our decision. In the case of negotiated exchange, prior research has found similar results with as few as 12 episodes (Lawler and Yoon 1993) and as many as 20 episodes (Lawler et al. 2006).
} 


\section{Manipulation of Forms of Exchange}

Across all conditions, the benefit from exchange and the expected value associated with each relation were constant and equal. Under all four forms of exchange, the expected value of what actors could receive from each viable exchange behavior is 800 points. If actors chose not to give to or exchange with anyone, they received a default payoff of300 points (i.e., this 300 points was forfeited if they gave to or exchanged in any viable relation). The default profit was part of the cover story designed to suggest that each company had the capacity to generate a flow of profit independent of the other companies. Because this default payoff was forfeited if they exchanged with or gave to another, it represents a constant and equal opportunity cost across the four experimental conditions. These costs and benefits were held constant at the relational level, that is, across all relations in all four conditions the gain from exchange is 800 points and the cost of exchange is 300 points. $^{7}$ The specifics for each condition are given below.

In negotiated exchange, actors negotiate with two prospective partners in the three-actor network at the same time, and each actor may reach an agreement with either, both, or neither partner. Each episode has up to three rounds of negotiation; in each round, actors could repeat their last offer or make a further concession by raising their offer. They could not retract earlier concessions. The negotiations continue until either an agreement is reached or the end of the third round. An agreement occurs if the sum of actors' claims or demands is equal to or less than the total amount of joint profit on each relation (i.e., 1,600). The expected payoff per relation is

\footnotetext{
${ }^{7}$ We used the default payoff to enhance the plausibility of the "cover story" and also to reduce the exogenous experimental pressure on subjects to exchange. This allows for more variation in giving rates, enhances our capacity to detect subtle differences in the emergence of micro order, and mirrors the opportunity or transaction costs associated with many exchanges outside the lab. It thus provides a conservative yet strong test of our hypotheses.
} 
800 points given all positions are of equal power. If an individual is excluded from any exchange, they receive the default 300 profit points for that episode.

The reciprocal exchange condition includes most of the elements and procedures Molm and colleagues used in their research on reciprocal and negotiated exchange (e.g., Molm et al. 1999). Exchange relations can form, but they involve cross-episode, sequential giving, rather than a within episode explicit agreement as with negotiated exchange. In a given episode, every actor simultaneously decides whether to give resources (valued at 800 profit points to the receiver) to one or both of their partners. If they do not give to either, they receive the default payoff of 300 points, as in the negotiated condition.

In the productive exchange condition, each subject simultaneously decides whether to invest 800 points in a common account. Resources flow to the account and benefits flow from it. This is similar to an assurance game in which the largest payoffs are from mutual cooperation (Kollock 1998). The payoffs from the joint venture are determined by the number who participate in the interaction. If only one person contributes, the 800 points are divided equally among the three actors such that each actor receives 266 points from the joint venture (of course, the two noncontributors also earn the 300 point default payoff). If two actors give, their total contributions $(800+800=1,600$ total $)$ are multiplied by 1.5 to generate 2,400 points. This amount is then divided equally across the three such that each receives 800 profit points (again, the noncontributor also earns the 300 point default). If all three contribute, their total contributions $(800+800+800=2,400)$ are doubled to yield 4,800 profit points. This amount is then divided equally across the three such that each receives 1,600 . The payoff is maximal when all three actors contribute and this amount is consistent with maximal payoffs in other conditions. 
In the generalized exchange condition, each subject can give to one other and receive from a different other. Individual contributions are structured such that A benefits B, B benefits C, and C benefits A (see Figure 1). An episode here consists of each subject simultaneously deciding whether or not to give resources to the contiguous other in the chain. ${ }^{8}$ To be consistent with the reciprocal condition and hold the relational payoffs constant, the points given to the other are valued at 800 profit points for the receiver. ${ }^{9}$ Also, as with all other conditions, if an individual decides not to give they receive the default payoff for that episode.

\section{Measures of Dependent Variables}

Our theory predicts the ranking across the forms of exchange for each empirical indicator of micro order: (1) the rates of giving in the network, (2) global feelings of pleasure/satisfaction, (3) perceptions of network cohesion, and (4) affective attachment to the network as a whole. We also measure specific emotions to test for the predicted ordering across the conditions.

\footnotetext{
${ }^{8}$ In both reciprocal and generalized exchange conditions subjects were explicitly told they are giving 400 points that will double to 800 points for the receiver. This procedure has been used in related research on reciprocal (Molm, Collett, and Schaefer 2006) and generalized exchange (Yamagishi and Cook 1993) and we included it for that reason. It has no bearing on the incentives of actors.

${ }^{9}$ By definition, in generalized exchange with a single-commodity, such as our triadic-chain, an actor can benefit from only one other actor. We thus adjusted the pay schedule here so that the total monetary value is equated with the other conditions. The expected value of profit (800) is equated at the level of the relation across all four forms of exchange. This means, however, that in a given episode within the generalized exchange condition actors could receive 800 points total, whereas they could receive 1,600 points maximum in the other conditions (800 points x 2 relations). To examine this, we ran an ancillary condition of generalized exchange in which subjects could receive 1,600 points (instead of 800 ). The substantive results across all four dimensions of micro order (giving behavior, global emotion, cohesion, and affective attachment) were nearly identical, and there were no significant differences between the two versions of the generalized exchange condition. These data are available from the authors upon request.
} 


\section{Behavioral Measures}

Proportion giving is the networkwide rate of giving behavior divided by the total number of opportunities (range $=0$ to 1 ). This is the most comparable behavioral measure across all forms of social exchange. In productive exchange it is giving to a group, in reciprocal it is giving to one or two others, in generalized it is giving to an adjacent other, and in negotiated it is reaching agreement with one or two others. ${ }^{10}$ We analyze the proportion of giving across all episodes and also by round block (first half, second half) to test for effects over time.

Profit difference is a control variable in the regression analyses testing the mediation hypothesis. This is measured at the network level as the average of the absolute difference in profits across the three relations. When all actors earn precisely the same profit this measure equals zero; when there is some profit differentiation the index equals a positive value. This measure essentially controls for the differences in the amount of rewards that actors receive over time.

\section{Questionnaire Measures}

The computer software administered three questionnaires: one at the midpoint, one near the end, and one at the end of the study. In the negotiated condition, the first questionnaire came after the eighth episode (after the 24th episode in the other conditions) and the second came after the 16th episode (after the 48th episode in all others). The measures on each questionnaire were

\footnotetext{
10 To illustrate, if each person in the reciprocal exchange conditions gave to only one other on every round, the proportion of exchange is .50; if they gave to both others on every round the proportion is 1.0 .
} 
based on the theorizing. Drawing on relational cohesion theory, we measured global emotions and perceived cohesion on the first questionnaire. We measured affective attachments on the third (post) questionnaire because the affect theory suggests they are an outcome. To test for changes in cohesion over time, we measured network cohesion on the second questionnaire. We also measured the specific emotions here because they follow the global emotions in the affect theory of exchange.

To measure global emotions the first questionnaire asked subjects to "describe your feelings right now” along a series of nine-point semantic-differential items: pleased-displeased, happy-unhappy, satisfied-not satisfied, contented-discontented, and joyful-not joyful. We averaged the scores within the network to create a single networkwide index (Cronbach's alpha = .93). ${ }^{11}$

We measured perceptions of network cohesion on the first and second questionnaires. Subjects were asked to "describe the network along each of the following”: close-distant, coming together-coming apart, solid-fragile, cohesive-divisive, and converging-diverging. Again, we averaged scores across members of the network to create a single network index. Previous work (Lawler et al. 2000; Lawler and Yoon 1993, 1996) documents that global emotions and perceptions of either relational or network cohesion are distinct constructs and highly reliable (Cronbach’s alpha $=.94)$.

The second questionnaire also measured the four specific emotions. These measures asked subjects to describe their feelings on a single nine-point scale directed at themselves (in the case of pride and shame) or nine-point scales directed at each of the others (in the case of

\footnotetext{
${ }^{11}$ For reasons outlined in Thye (2000b), we reported reliability estimates as weighted averages across the four experimental conditions.
} 
gratitude and anger). The anchors for each Likert item were: proud-not proud, grateful-not grateful, angry-not angry, and shameful-shameless.

At the end, subjects received a post questionnaire containing the measure of affective attachments to the group. The items (five) asked subjects how they feel about their relationship to the group, and they responded on the following nine-point scales: bad-good, attacheddetached, disloyal-loyal, disconnected- connected, and negative-positive. We created networklevel scores by averaging individual ratings (Cronbach’s alpha $=.90) .{ }^{12}$ Finally, as a check on the logic of the theory, a single item measured perceptions of shared responsibility as follows: "When satisfactory results were produced in the episodes, to what extent did you and the others share joint responsibility?” Subjects responded on a nine-point scale, from "not at all” to "very much.”

Insert Table 2

\section{RESULTS}

The results are divided into three sections: (1) analyses of variance to assess the main hypotheses, (2) a supplemental repeated-measures analysis of variance to test for trends in rates

${ }^{12}$ A confirmatory factor analysis indicates that affective attachment to the group is distinct from global emotions and relational cohesion. The best fitting model occurs when each of the three factors is treated as a distinct construct (chi-square $=385$, $\mathrm{df}=76$ ). In comparison, the goodnessof-fit index drops significantly when the three measures are treated as a single construct (chisquare $=1325, \mathrm{df}=77$ ). The best performing two-factor model occurs when relational cohesion is combined with affective attachment (chi-square $=373$, $\mathrm{df}=76$ ). Together, this evidence suggests the three constructs are theoretically and empirically distinct. 
of giving and network cohesion, and (3) ordinary least squares regression models to test the mediation hypothesis.

\section{Micro Social Order: Hypotheses 1 to 4}

We use one-way analyses of variance (ANOVA) to examine the impact of the four structural forms of exchange on the four indicators of micro order: exchange frequency, global emotions, perceptions of network cohesion, and affective attachments to the social unit. Table 2 contains the means, ANOVA results, and post hoc tests that control the overall Type I error rate.

There are significant main effects of exchange structure on all four dimensions of micro order: the proportion of giving (F3 $60=20.19$, $p<.001)$, the strength of global emotion $\left(F_{3,60}=\right.$ 21.21, $p<.001)$, perceptions of network cohesion $\left(F_{3,60}=21.24, p<.001\right)$, and affective attachments to the group $\left(F_{3,60}=14.95, p<.001\right)$. Moreover, the post hoc tests find the exact same pattern for each variable. In every case, the productive exchange structure is greater than the two direct forms of exchange (negotiated and reciprocal), which are greater than the generalized-exchange structure. The only departure from the theory is that there are no significant differences between negotiated and reciprocal forms of exchange.

The logic underlying the affect theory asserts that different structures of exchange promote different degrees of shared responsibility for the results of the interaction. An ANOVA on perceptions of shared responsibility reveals a significant main effect for exchange structure that affirms the expected pattern $\left(F_{3,60}=14.54, p<.001\right.$; productive $\mathrm{M}=7.9$, negotiated $\mathrm{M}=$ 6.6, reciprocal $M=6.2$, and generalized $M=5.7$ ). The follow-up tests dovetail with those for micro order. Productive exchange produces a greater sense of shared responsibility than do the 
forms of direct exchange (negotiated and reciprocal), and the direct forms of exchange generate a greater sense of shared responsibility than does generalized exchange. Negotiated and reciprocal forms of exchange are not significantly different from one another, which may explain the lack of other differences between these forms. Overall, the results for shared responsibility (1) affirm a core proposition that enables the theory to make predictions for forms of exchange and (2) mirror perfectly the results for micro social order. ${ }^{13}$

In sum, the results provide clear and consistent support for the affect theory. Productive exchange generates the highest rates of giving, the strongest positive emotion, greater perceptions of network cohesion, and the greatest affective attachment to the overall network. Generalized exchange produces the lowest levels (i.e., weakest micro order) on all of these dimensions. Productive exchange also generates the greatest sense of shared responsibility, whereas generalized exchange produces the least. The direct forms of exchange consistently fall between these extremes. The fact that generalized exchange produces weaker indications of micro order than do direct forms of exchange is contrary to some prior theorizing (Ekeh 1974; Molm 2003a).

Although predicted, we find no difference between negotiated and reciprocal exchange. However, given Molm’s (2003a, 2003b) research showing that reciprocal exchange fosters more commitment than negotiated exchange, it is not surprising that the affect theory of social exchange fails here. We must note, though, that Molm’s (20003a, 2003b) negotiated < reciprocal

\footnotetext{
13 To further examine the role of shared responsibility, we regressed affective attachments on perceptions of shared responsibility, controlling for exchange frequency, profit differences, and the forms of exchange. The results indicate a significant impact of shared responsibility on affective attachments $(\mathrm{B}=.339, \mathrm{p}<.01)$, as suggested by the affect theory. In the context of the results for the forms of exchange and micro order, this adds further support to the underlying logic of the theory.
} 
prediction is also not supported, which raises a question about the conditions under which negotiated-reciprocal differences are likely to occur. We return to this issue in the discussion.

\section{Over Time Effects}

To further pursue the difference between productive and generalized exchange, we examined the trends over time for giving behavior and for perceived network cohesion using a repeated-measures analysis of variance. It is plausible that differences between productive and generalized exchange may occur early but then converge and “wash out” over time. For this analysis, we divided rates of giving into two time blocks (i.e., 24 episodes in each block for productive, reciprocal, and generalized; eight episodes each for negotiated) and analyzed the two measures of perceived cohesion (i.e., at the 24th and 48th episodes; and the 8th and 16th in negotiated exchange). Figure 2 shows the trends for giving behavior.

The repeated-measures ANOVA for exchange (giving) behavior does not reveal an interaction effect between time block and exchange structure on giving behavior $\left(F_{7,120}<1 ; p=\right.$ n.s.). The differences across forms of exchange emerge early and remain relatively steady. A more refined analysis, dividing the blocks into four periods, also does not show an interaction effect between exchange structure and time $(\mathrm{F}<1 ; p=$ n.s.). The upshot is that rates of exchange or giving behavior are relatively steady over time across all conditions.

In contrast, the repeated-measures ANOVA for perceptions of network cohesion reveals a significant interaction effect $\left(F_{3,120}=4.65, p<.01\right)$, along with the main effect already reported $\left(F_{3,120}=31.64, p<.001\right)$. Figure 3 illustrates the pattern. Perceptions of network cohesion became stronger over time in productive exchange (Means $=6.27$ to $7.18, t_{63}=6.13, p<.001$ ), 
but they deteriorate in generalized exchange (Means $=4.60$ to 3.42, $t_{63}=7.12, p<.001$ ).

Negotiated and reciprocal exchange generate similar levels of cohesion over time and there were no significant differences $($ Means $=5.79$ to 5.44 in negotiated; Means $=5.78$ to 5.56 in reciprocal). The fact that productive exchange produces a strengthening of network-level cohesion and generalized exchange produces a weakening of cohesion is consistent with the idea that productive exchange has greater potential to endogenously generate micro social order.

\section{Emotions Directed at Self and Other (Hypotheses 5 and 6)}

Table 3 shows the means and analyses of variance for specific emotions directed at self and others. These effects are generally consistent with Hypotheses 5 and 6. There are significant main effects for gratitude toward the others $\left(F_{3,60}=23.51, p<.001\right)$, for pride in self $(\mathrm{F} 360=$ 13.12, $p<.001)$, for anger toward the others $\left(F_{3,60}=19.85, p<.001\right)$, and for shame in self $\left(F_{3,60}=15.79, p<.001\right)$. Productive exchange produces the greatest gratitude toward the others, the greatest expression of pride in self, and the lowest levels of anger and shame. In contrast, generalized exchange produces the least gratitude and the most anger toward the others, as well as a similar trend with respect to pride and shame toward self.

Insert Figure 2

Insert Table 3 


\section{Insert Figure 3}

Three other patterns are worthy of note. First, comparing generalized to each direct form of exchange, six of the eight differences are significant and support the theory. Generalized exchange fosters more anger and shame, as well as less pride and gratitude, than did reciprocal exchange. Pride and shame in generalized exchange, however, were not different from negotiated exchange. Second, contrary to the affect theory, negotiated exchange produces more anger and less gratitude toward the other than did reciprocal exchange. These findings support the implications of Molm’s (2003a, 2003b; Molm et al. 2007) research indicating that negotiated exchange produces less positive affect directed at the exchange partner. Third, there is no difference between anger and shame under generalized exchange and thus no evidence for selfserving attributions therein.

\section{Test of Mediating Process (Hypothesis 7)}

To conduct an OLS analysis of the indirect effects of forms of exchange, we created a set of dummy variables to capture the four forms of exchange. We then regressed giving behavior, global emotions, and perceived network cohesion on these dummies. To make the analysis comparable to related research (Lawler et al. 2000; Lawler and Yoon 1996), we included three 
additional controls: profit differentiation, perceived predictability, and interest/excitement, an emotion used in relational cohesion research. ${ }^{14}$ Table 4 shows the results.

First, recall that the ANOVA results in Table 2 establish that the form of exchange significantly impacts giving behavior. The left most equation in Table 4 indicates that giving behavior has the largest effect on global feelings of pleasure (Beta $=.543, p<.001)$. Second, the central equation indicates that these global feelings measured at time 1 have a positive (though marginal) effect on perceptions of cohesion measured at time 2 (Beta $=.221, p<.10$ ). Third, the right equation finds that perceived network cohesion has the largest effect on affective attachments (Beta $=.453, p<.001) .{ }^{15}$ The first two findings replicate principles of relational cohesion theory. The third finding shows how these effects also mediate the path from exchange behavior to affective attachments as the affect theory would suggest. Importantly, the effects of exchange behavior on positive emotions are strong, as are the effects of network cohesion on affective attachments to the group. ${ }^{16}$ This confirms key junctures in the integration of relational cohesion principles into the affect theory of social exchange.

\footnotetext{
14 The measure of interest/excitement index is identical to that from prior research on relational cohesion (Lawler et al. 2000; Lawler and Yoon 1996, 1998). The index consists of items with the following anchors: enthusiastic-unenthusiastic, exciting-boring, motivating-not motivating, and interesting-not interesting. The measure of perceived predictability consists of Likert scale items with the following anchors: unpredictable-predictable, uncertain-certain, vague-clear, and ambiguous-unambiguous.

15 The marginal effect for global feelings may be due to the lag between time 1 (when the emotions were measured) and time 2 (when cohesion was measured). If we substitute the time 1 measure of cohesion for the time 2 measure, global feelings of pleasure have a sizeable, positive effect on the perceived cohesion (Beta $=.301, p<.01$ ) and the other results do not change significantly. This trend is consistent with prior research (Lawler et al. 2000; Lawler and Yoon 1996).

${ }^{16}$ Also of note, the zero order correlations between giving in the first block of episodes and global emotions (measured at the end of this block) indicate that giving behavior has a significant correlation with positive emotions in productive exchange $(\mathrm{r}=.11, p<.01)$, and the correlations in reciprocal $(\mathrm{r}=.64, p<.01)$ and negotiated $(\mathrm{r}=.77, p<.001)$ are similar to those for productive exchange. However, with a generalized exchange structure, the correlation of
} 


\section{Insert Table 4}

\section{DISCUSSION AND CONCLUSIONS}

Micro social orders emerge from and are sustained by a structure-interaction process or dynamic. Structure shapes who interacts with whom and how often. The resulting patterns of interaction in turn generate a realized social order, or stable set of ties among actors. The concept of micro social order, as we conceive it, captures the joint consequences of a "dialectic” between structure and interaction. Micro social orders lack the standard properties of full- fledged groups (i.e., group goals, norms, or hierarchical structure), yet they involve more than the minimal or purely “categorical groups” of social identity theory (e.g., Hogg 2001). In this sense, they occupy a space between purely cognitive groups and groups with explicit goals and organized activities. In this article, we analyze how and when structural forms of exchange within networks promote the emergence of micro orders at the network level.

Social exchange theory developed in sociology as a decidedly micro tradition focused on how individuals interact and, in particular, on the rewards they provide to each other. Social exchange theory adopts an instrumental view of the human actor and a transactional view of

giving behavior and positive emotions is not significant ( $\mathrm{r}=.24, p=\mathrm{n} . \mathrm{s}$.). Under generalized exchange, there is no evidence for an effect of exchange (giving) behavior on positive emotions. Finally, we conducted a regression with giving proportion in the four episodes preceding the post questionnaire, and these results were generally consistent with the results for affective attachment-namely, perceptions of network cohesion had a significant effect on giving rate in the last four episodes (Beta $=.295, p<.01)$. 
social interaction (Blau 1964; Emerson 1972a, 1972b; Homans 1961; Molm and Cook 1995). These simplifying assumptions about actors and interaction are a source of theoretical strength, in part, because they enhance the capacity of exchange theories to address or be integrated with macro-sociological traditions or fields such as organizations (e.g., interorganizational ties), stratification (e.g., social inequality), or economy and society (e.g., social embeddedness) (Cook et al. 2005; Nee and Ingram 1998; Pfeffer 1981; Uzzi and Lancaster 2004). The affect theory of social exchange (Lawler 2001, 2002) begins with a different model of human actors, arguing that people are feeling, affective beings who form expressive attachments to relations and groups within which they interact and exchange rewards. Emotions are internal events that, in Bandura's (1977) terms, are self-reinforcing, and in exchange-theory terms, are internal, self-generated rewards or punishments. The affect theory essentially connects the instrumental and rational components of action, which are assumed in the exchange tradition, to the emotional and expressive components assumed by sociological theories of emotion (e.g., Collins 2004; Heise 1979; Ridgeway and Johnson 1990; Smith-Lovin and Heise 1988; Turner 2000, 2002).

The unique and most fundamental question posed by the affect theory of social exchange is: Under what conditions do actors attribute their emotional experiences to a social unit? The social unit may be a relation, group, network, firm, organization, community, or even a society. The theory puts forth a general process that, in principle, should apply to any social unit of import to the interactions of actors. The theory contends that actors are likely to attribute their emotions to social units that organize or shape those tasks, especially if the tasks or activities are jointly undertaken and accomplished. Theoretically, these could be local, immediate units or larger and more distant units (see Collins 2004; Lawler 1992; Turner 2002; Yoon and Thye 2002). In either case, social-unit attributions of emotion are important because they strengthen 
person-to-group attachments and, insofar as these attachments have an emotional character, they make that unit an object of value. The argument is fairly straightforward: To the degree that actors infer shared responsibility from the structures of interaction, social unit attributions are likely and person-to-group attachments should flourish and grow. The result is more grouporiented cognition, affect, and behavior than is implied by standard incentive or reward-based explanations.

In this research, we applied these principles to four structural forms of social exchange found in the literature (Emerson 1972a, 1972b, 1981; Lawler 2001; Molm 1994; Molm and Cook 1995): productive, negotiated, reciprocal, and generalized. The main prediction from the affect theory is that the strength of a micro social order will vary based on the degree that the task involves nonseparable (indistinguishable) contributions and produces a high sense of shared responsibility. Productive exchange should thus yield the strongest micro social order, whereas generalized should yield the weakest micro order. Both negotiated and reciprocal exchange should fall in between productive and generalized, and they do. Negotiated exchange, however, does not produce stronger micro social order than reciprocal exchange as we anticipated.

Our results consistently support core predictions, except for the lack of difference between the negotiated and reciprocal forms. First, as expected, productive exchange generated the highest rates of exchange, the strongest feelings of pleasure, the greatest sense of networklevel unity or cohesion, and the strongest affective attachments to the network as a group. Second, generalized exchange produced the lowest rates of these phenomena. Third, across time, perceived network cohesion increased under productive exchange but declined under generalized exchange, suggesting the potential of the former to naturally generate micro orders. Fourth, and as expected, the two direct forms of social exchange—negotiated and reciprocal—-were 
significantly different from and fell between productive and generalized exchange on all of the micro-order dimensions studied here. As a whole, the results reveal a strikingly consistent pattern across all relevant dimensions or indicators of micro social order.

The finding that generalized exchange produces the lowest proportion of giving behavior and the lowest perceived network cohesion is inconsistent with Ekeh's (1974) theorizing and some related research on generalized exchange (e.g., Bearman 1997; Molm et al. 2007; Yamagishi and Cook 1993). Repeated opportunities to exchange in the generalized structure did not generate a high proportion of exchange behavior (giving) among members (see Buchan, Croson, and Dawes [2002] for similar results in a one-shot exchange). Ekeh's (1974) collectivist concept of exchange, however, presumes a larger normative framework and extant person- togroup ties within which exchanges occur. This may explain why generalized exchange produced a weak micro order in our study. Our experiment removed such factors given that our intention was to compare the capacity of the four forms of exchange to generate person-to-group ties, endogenously. In the collectivist framework, person-to-group ties are essentially reaffirmed or symbolized by local micro social orders. In the individualist framework, person- to-group ties are an emergent "collective” result of a structure-interaction dynamic. In this vein, our research identifies a process by which individualist conditions of exchange evolve toward collectivist conditions.

We suspect that for generalized exchange to produce an emergent micro order, some form of exogenous "spark” or structural push is needed. Theoretically possible candidates include (1) a common group identity or affiliation (Tajfel and Turner 1986), (2) a norm of generalized reciprocity (Gouldner 1960; Nee and Ingram 1998), (3) cultural beliefs that foster generalized trust in others (Fukuyama 1995; Yamagishi, Cook, and Watabe 1998), (4) a sense of 
individual accountability or responsibility (Fox and Guyer 1978; Jerdee and Rosen 1974), or (5) a lack of opportunity cost associated with giving behavior (see Molm et al. 2007). ${ }^{17}$ In this regard, our experiment suggests that, compared with other forms of exchange, the structural capacity of generalized exchange to generate emergent orders is lower, probably because, in its most abstract form, such a spark is lacking. Future research should theorize and investigate the conditions under which generalized exchange will generate weak versus strong micro orders. ${ }^{18}$ The individualist (Emerson 1972a; Homans 1950, 1961; Thibaut and Kelley 1959) and collectivist approaches to social exchange make different assumptions about the initial conditions for social exchange. The key problem for the collectivist approach is to understand the ties and connections between the "local” exchange processes and a larger collective or institutional framework. Sustained exchange is not possible, or expected, without the larger exogenous framework. The individualist approach (Blau 1964; Emerson 1972a; Homans 1961; Thibaut and Kelley 1959) makes simplified and relatively sparse a priori assumptions about the structural context within which exchange takes place. Relations and groups ostensibly are built and sustained from the "ground up” by repeated social interactions (e.g., Homans 1950) made

${ }^{17}$ Molm and colleagues (2007) report one experimental condition on generalized exchange using a cost not unlike our default payoff. They find that the rate of giving in generalized falls from .81 to .41 when giving involves a cost. This is consistent with the rate of giving we report here $(\mathrm{M}=$ .32) and also that found in a recent replication (Triplett and Thye 2007) of our generalized exchange condition $(\mathrm{M}=.27)$.

${ }^{18}$ An alternative to the "spark" hypothesis is that generalized exchange produces weaker micro social order when the network ties entail null connections, that is, people can interact or exchange with anyone they are connected to. On the other hand, generalized exchange produces stronger micro order when the networks are exclusively or negatively connected. In the former (representing our study), people can exchange with up to two others under negotiated and reciprocal exchange but only one other under generalized exchange; whereas in the latter (representing the research of Molm and colleagues), negotiated and reciprocal exchange involve conflict because one party must be excluded. These structural conditions could account for the differences between our results for generalized exchange and those of Molm and colleagues. 
possible by structural conditions. From our theory, exogenous effects operate through the sharedresponsibility mechanism.

The only departure from the theory's predictions is the lack of differences between negotiated and reciprocal exchange across the dimensions of micro order. Our prediction (negotiated $>$ reciprocal) is based on the propensity for negotiated exchange to produce a greater sense of shared responsibility compared with reciprocal exchange. In Molm’s theory, reciprocal exchange has stronger effects than negotiated because the salience of conflict is lower in the former and people make more positive inferences about a partner who gives unilaterally as opposed to one who agrees to negotiated contract terms (Molm 2003a, 2003b). From our theory, the most plausible explanation is that the negotiated exchange condition did not generate a greater sense of shared responsibility. From Molm’s theory, it is possible that negotiated and reciprocal exchanges did not differ because the salience of conflict did not differ. Recall, however, that we have some evidence in support of Molm’s theory-namely, that reciprocal exchange produced more gratitude toward exchange partners (and less anger) than did negotiated exchange.

Our interpretation is that "null” networks substantially reduced the salience of conflict difference between negotiated and reciprocal exchange because all actors can be included in all exchanges under both regimes. We thus found no differences in micro order between negotiated and reciprocal exchange because the conditions for such effects, specified by either theory, were not present. Neither shared responsibility nor the salience of conflict differed across these conditions. This interpretation leads to the hypothesis that differences between negotiated and reciprocal exchange are contingent on differences in either the salience of conflict or perceptions of shared responsibility. If only the former occurs, reciprocal forms of exchange should generate 
stronger micro orders than would negotiated exchange. If only the latter occurs, negotiated exchange should generate stronger micro orders than would reciprocal exchange. If there are differences along both dimensions, the impact of reciprocal versus negotiated exchange is determined by the relative importance or weight people accord these differences.

To summarize, this article shows how different forms of social interaction or exchange affect the emergence of a micro social order in a social network. Each form of exchange entails a distinct type of connection between the behaviors at the heart of social exchange processes. Productive exchange interweaves individual behaviors to generate a collective joint product. Direct forms of exchange either involve an explicit contract specifying what each actor is to give (negotiated) or an implicit contingency between unilateral acts of giving at different times (reciprocal). Generalized exchange involves a chain of unilateral acts of giving. Our research demonstrates that productive forms of exchange produce the strongest order at the micro level. Overall, our theory and research illuminate how structure-interaction dynamics can endogenously generate micro social orders and self-collectivity ties that are affectively-based and infused with expressive value. 
Figure 1

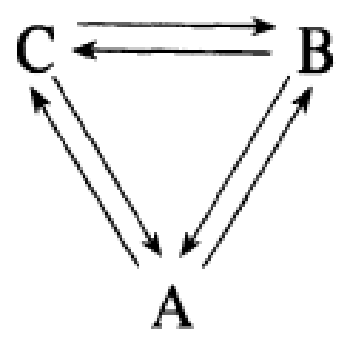

\section{Reciprocal}

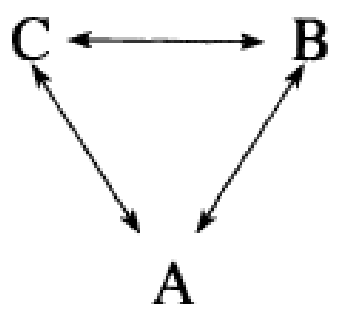

Negotiated

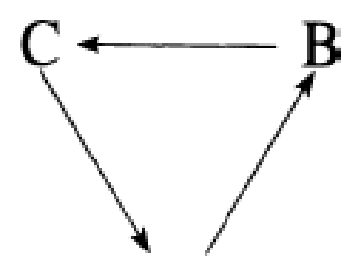

A

Generalized

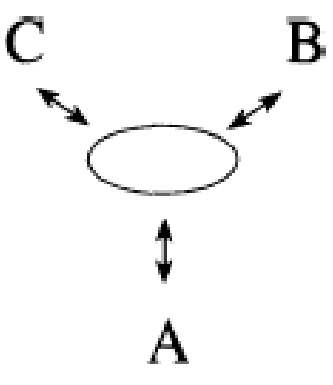

Productive

Figure 1. Diagram of Four Forms of Social Exchange 
Figure 2

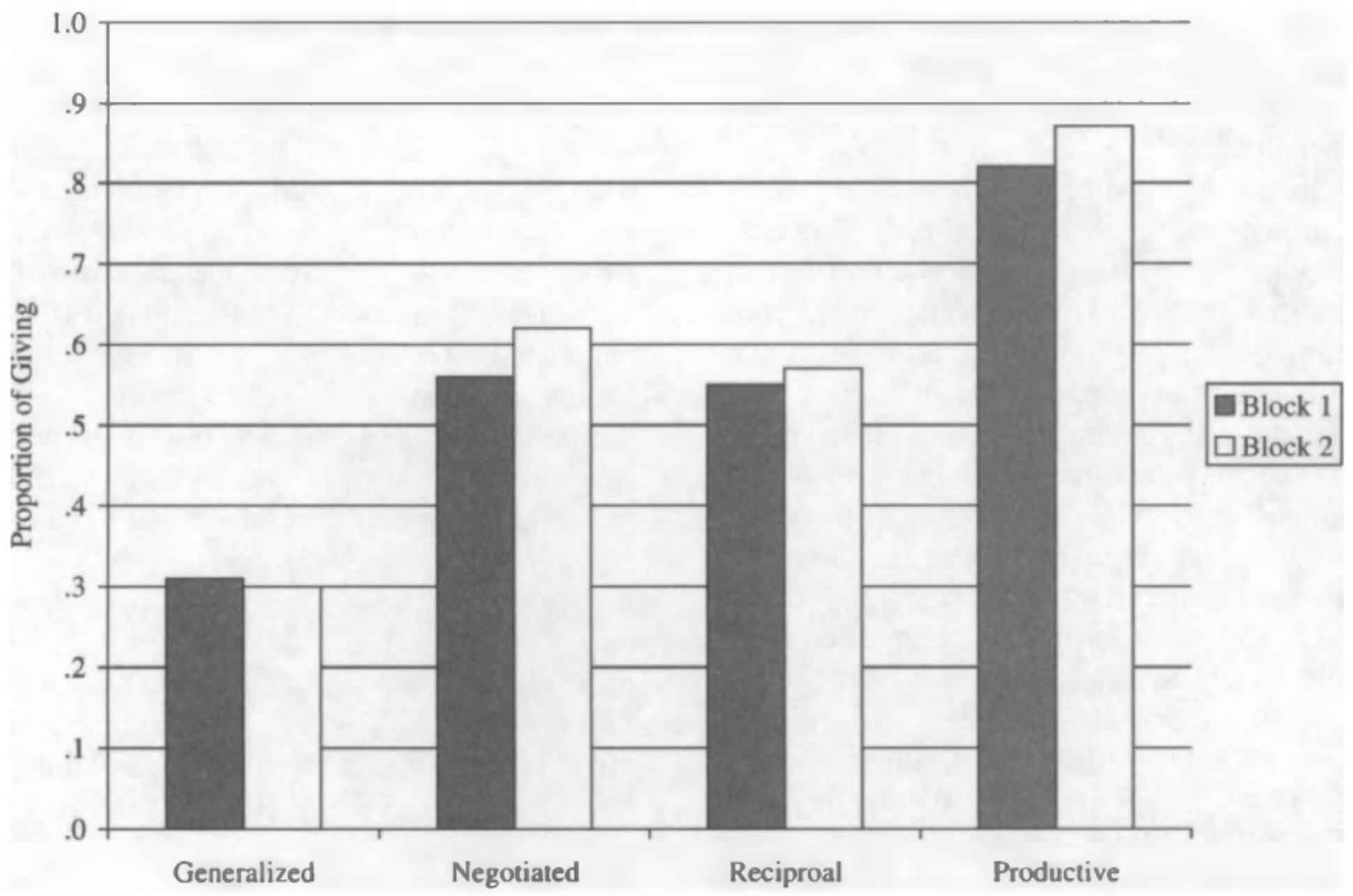

Figure 2. Proportion of Giving across Two Episode Blocks 
Figure 3

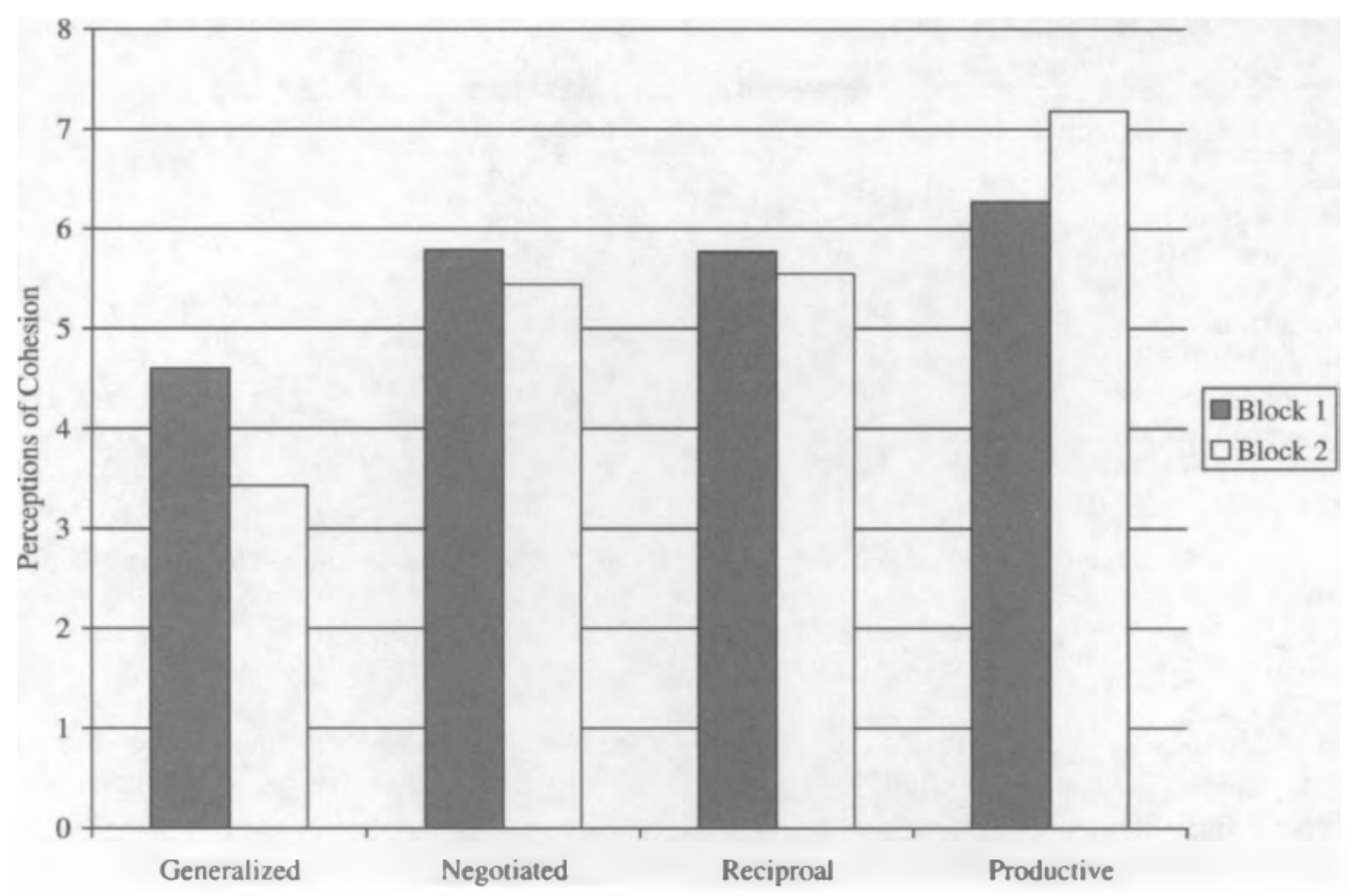

Figure 3. Perceptions of Network Cohesion across Two Episode Blocks 
Table 1

Table 1. Emotions Directed at Each Object

\begin{tabular}{lcc}
\hline \hline & & Valence of Emotion \\
\hline Social Object & Positive & Negative \\
Task & Pleasantness & Unpleasantness \\
Self & Pride & Shame \\
Other & Gratitude & Anger \\
Social Unit & Affective Attachment & Affective Detachment \\
\hline
\end{tabular}

Note: Reprinted from An Affect Theory of Social Exchange (Lawler 2001). 
Table 2

Table 2. Means and Analysis of Variance for Key Measures across Conditions

\begin{tabular}{lcccc}
\hline & \multicolumn{4}{c}{ Experimental Condition } \\
\cline { 2 - 5 } & Generalized & Reciprocal & Negotiated & Productive \\
\hline $\begin{array}{l}\text { Global Emotion } \\
\quad F_{3,60}=21.21^{* * *}\end{array}$ & $4.49(.95)^{\mathrm{a}}$ & $6.17(.87)^{\mathrm{b}}$ & $5.37(1.02)^{\mathrm{b}}$ & $7.10(1.01)^{\mathrm{c}}$ \\
$\begin{array}{c}\text { Proportion of Giving } \\
\quad F_{3,60}=20.19^{* * *}\end{array}$ & $.32(.19)^{\mathrm{a}}$ & $.56(.20)^{\mathrm{b}}$ & $.61(.16)^{\mathrm{b}}$ & $.84(.22)^{\mathrm{c}}$ \\
$\begin{array}{c}\text { Network Cohesion } \\
\quad \mathrm{F}_{3,60}=21.24^{* * *}\end{array}$ & $3.43(1.51)^{\mathrm{a}}$ & $5.56(1.27)^{\mathrm{b}}$ & $5.44(1.27)^{\mathrm{b}}$ & $7.18(1.26)^{\mathrm{c}}$ \\
$\begin{array}{c}\text { Group Attachment } \\
\quad F_{3,60}=14.95^{* * *}\end{array}$ & $4.32(1.08)^{\mathrm{a}}$ & $5.76(.86)^{\mathrm{b}}$ & $5.55(.81)^{\mathrm{b}}$ & $6.57(1.07)^{\mathrm{c}}$ \\
$\mathrm{N}$ & 16 & 16 & 16 & 16 \\
\hline
\end{tabular}

Notes: Standard deviations are in parentheses. Cells in a given row with different letters are significantly different at the .05 level or greater using Duncan's Multiple Range Test for pairwise comparisons. 
Table 3

Table 3. Means and Analysis of Variance for Specific Emotions across Conditions

\begin{tabular}{lcccc}
\hline & \multicolumn{4}{c}{ Experimental Condition } \\
\cline { 2 - 5 } & Generalized & Reciprocal & Negotiated & Productive \\
\hline $\begin{array}{l}\text { Gratitude toward Other } \\
\mathrm{F}_{3,60}=23.51^{* * *}\end{array}$ & $4.00(1.36)^{\mathrm{a}}$ & $6.07(1.18)^{\mathrm{b}}$ & $5.00(1.08)^{\mathrm{c}}$ & $7.40(1.18)^{\mathrm{d}}$ \\
$\begin{array}{c}\text { Pride in Self } \\
\quad \mathrm{F}_{3,60}=13.12^{* * *}\end{array}$ & $5.46(.94)^{\mathrm{a}}$ & $6.27(.90)^{\mathrm{b}}$ & $5.77(1.02)^{\mathrm{ab}}$ & $7.27(.59)^{\mathrm{c}}$ \\
$\begin{array}{c}\text { Anger toward Other } \\
\quad \mathrm{F}_{3,60}=19.85^{* * *}\end{array}$ & $4.17(1.22)^{\mathrm{a}}$ & $2.33(1.55)^{\mathrm{b}}$ & $3.24(.86)^{\mathrm{c}}$ & $.98(1.14)^{\mathrm{d}}$ \\
$\begin{array}{l}\text { Shame toward Self } \\
\mathrm{F}_{3,60}=15.79^{* * *}\end{array}$ & $3.08(1.16)^{\mathrm{a}}$ & $2.23(.83)^{\mathrm{b}}$ & $2.58(.83)^{\mathrm{ab}}$ & $1.04(.58)^{\mathrm{c}}$ \\
$\mathrm{N}$ & 16 & 16 & 16 & 16 \\
\hline
\end{tabular}

Notes: Standard deviations are in parentheses. Cells in a given row with different letters are significantly different at the .05 level or greater using Duncan's Multiple Range Test for pairwise comparisons. 
Table 4

Table 4. Standard OLS Regression Coefficients Regressing Network Cohesion and Attachment on Antecedent Variables with Perceived Predictability Controlled

\begin{tabular}{lccc}
\hline Independent Variables & Global Emotions & Network Cohesion & Affective Attachment \\
\hline Generalized Exchange & $-.330^{* *}$ & $-.262^{*}$ & -.035 \\
Negotiated Exchange & $-.345^{* * *}$ & -.016 & .011 \\
Reciprocal Exchange & -.017 & -.115 & .052 \\
Proportion of Giving & $.543^{* * *}$ & $.465^{* * *}$ & .203 \\
Profit Difference & -.099 & -.139 & .008 \\
Pleasure/Satisfaction & & .221 & .156 \\
Interest/Excitement & & .04 & .05 \\
Perceived Predictability & & -.107 & .087 \\
Network Cohesion & .7 & .69 & $.452^{* * *}$ \\
$\mathrm{R}^{2}$ & & .7 & .7 \\
\hline
\end{tabular}

Notes: Generalized exchange, negotiated exchange, and reciprocal exchange are dummy variables. The omitted category is productive exchange.

${ }^{*} p<.05 ;{ }^{* *} p<.01 ;{ }^{* * *} p<.001$ (one-tailed tests). 


\section{References}

Bandura, Albert. 1977. Social Learning Theory. Englewood Cliffs, NJ: Prentice-Hall.

Bearman, Peter. 1997. “Generalized Exchange.” American Journal of Sociology 102(5): 1383-

1415. Benford, Robert D. and David A. Snow. 2000. "Framing Processes and Social Movements: An Overview and Assessment.” Annual Review of Sociology 26:611-39.

Berger, Peter and Thomas Luckmann. 1967. Social Construction of Reality. New York: Anchor Books.

Blau, Peter. 1964. Exchange and Power in Social Life. New York: Wiley.

Brennan, John S. 1981. “Some Experimental Structures.” Pp. 189-204 in Networks: Exchange and Coercion, edited by D. Wilier and B. Anderson. New York: Elsevier/Greenwood.

Brewer, Marilynn B. and Wendi Gardner. 1996. “Who is this 'We?’ Levels of Collective Identity and Self Representations.” Journal of Personality and Social Psychology 71(l):83-93.

Buchan, Nancy R., Rachel Croson, and Robyn M. Dawes. 2002. "Swift Neighbors and Persistent Strangers: A Cross-Cultural Investigation of Trust and Reciprocity in Social Exchange.” American Journal of Sociology 108(1): 168-206.

Burke, Peter J. 1991. “Identity Processes and Social Stress.” American Sociological Review 56(6):836-49.

Burt, Ronald S. 1978. “Cohesion Versus Structural Equivalence as a Basis for Network Subgroups.” Sociological Methods \& Research 7(2): 189-212.

Clore, Gerald L., Norbert Schwarz, and Michael Conway. 1994. “Affective Causes and Consequences of Social Information Processing.” Pp. 323-417 in Handbook of Social Cognition, Vol. 1, edited by R. S. Wyer and T. K. Srull. Hillsdale, NJ: Erlbaum. 
Coleman, James S. 1990. Foundations of Social Theory. Cambridge, MA: Harvard University Press.

Collins, Randall. 2004. Interaction Ritual Chains. Princeton, NJ: Princeton University Press.

Cook, Karen S. 2005. "Networks, Norms, and Trust: The Social Psychology of Social Capital.” Social Psychology Quarterly 68(1):4-14.

Cook, Karen S. and Richard M. Emerson. 1978. "Power, Equity and Commitment in Exchange Networks.” American Sociological Review 43(5):721-39.

Cook, Karen S., Richard M. Emerson, Mary R. Gillmore, and Toshio Yamagishi. 1983. “The Distribution of Power in Exchange Networks: Theory and Experimental Results.” American Journal of Sociology 89(2):275-305.

Cook, Karen S., Russell Hardin, and Margaret Levi. 2005. Cooperation Without Trust? New York: Russell Sage Foundation.

Damasio, Antonio R. 1999. The Feeling of What Happens: Body and Emotion in the Making of Consciousness. New York: Harcourt Brace.

---------. 2001. “Fundamental Feelings.” Nature 413:781.

Durkheim, Emile. [1893] 1997. The Division of Labor in Society. New York: Free Press.

Ekeh, Peter. 1974. Social Exchange Theory. Cambridge, MA: Harvard University Press.

Emerson, Richard M. 1972a. “Exchange Theory Part I: A Psychological Basis for Social Exchange.” Pp. 38-57 in Sociological Theories in Progress, edited by J. Berger, M. Zelditch Jr., and B. Anderson. Boston, MA: Houghton-Mifflin. 1972b. “Exchange Theory Part II: Exchange Relations and Networks.” Pp. 58-87 in Sociological Theories in Progress, edited by J. Berger, M. Zelditch Jr., and B. Anderson. Boston, MA: Houghton-Mifflin. 
---------. 1981. “Social Exchange Theory.” Pp. 30-65 in Social Psychology: Sociological Perspectives, edited by M. Rosenberg and R. H. Turner. New York: Basic Books. Fox, John and Melvin Guyer. 1978. “'Public’ Choice and Cooperation in n-Person Prisoner’s Dilemma.” The Journal of Conflict Resolution 22(3):469-81.

Fukuyama, Francis. 1995. Trust: The Social Virtues and the Creation of Prosperity. New York: Free Press.

Giddens, Anthony. 1984. The Constitution of Society: Outline of the Theory of Structuration. Berkeley, CA: University of California Press.

Goffman, Irving. 1959. The Presentation of Self in Everyday Life. New York: Doubleday. Gouldner, Alvin W. 1960. “The Norm of Reciprocity: A Preliminary Statement.” American Sociological Review 25(2): 161-78.

Granovetter, Mark. 1985. “Economic Action and Social Structure: The Problem of Embeddedness.” American Journal of Sociology 91:482-510.

Hechter, Michael. 1987. Principles of Group Solidarity. Berkeley, CA: University of California Press.

Heise, David R. 1979. Understanding Events: Affect and the Construction of Social Action. New York: Cambridge University Press.

Hochschild, Arlie Russell. 1979. “Emotion Work, Feeling Rules, and Social Structure.” American Journal of Sociology 85(3):551-75.

Hogg, Michael A. 2001. "Self-Categorization and Subjective Uncertainty Resolution: Cognitive and Motivational Facets of Social Identity and Group Membership.” Pp. 323-49 in The Social Mind: Cognitive and Motivational Aspects of Interpersonal Behavior, edited by J. P. Forgas, K. D. Williams, and L. Wheeler. New York: Cambridge University Press. 
---------. 2004. “Social Categorization, Depersonalization, and Group Behavior.” Pp. 202-31 in Self and Social Identity, edited by M. B. Brewer and M. Hewstone. Malden, MA: Backwell Publishers.

Homans, George Caspar. 1950. The Human Group. New Brunswick, NJ: Transaction Publishers. 1961. Social Behavior: Its Elementary Forms. New York: Harcourt, Brace \& World.

Izard, Carroll E. 1991. The Psychology of Emotions. New York: Plenum Press.

Jerdee, Thomas H. and Benson Rosen. 1974. “Effects of Opportunity to Communicate and Visibility of Individual Decisions on Behavior in the Common Interest.” Journal of Applied Social Psychology 59:712-16.

Jones, Edward E. and Keith E. Davis. 1965. "From Acts to Dispositions: The Attribution Process in Person Perception.” Pp. 219-66 in Advances in Experimental Social Psychology, Vol. 2, edited by L. Berkowitz. New York: Academic Press.

Kelley, Harold H. 1967. “Attribution Theory in Social Psychology.” Pp. 220-66 in Nebraska Symposium on Motivation, Vol. 15, edited by D. Levine. Lincoln, NE: University of Nebraska Press.

Kemper, Theodore D. 1978. A Social Interactional Theory of Emotions. New York: Wiley. Kollock, Peter. 1994. “The Emergence of Exchange Structures: An Experimental Study of Uncertainty, Commitment, and Trust.” American Journal of Sociology 100(2):313-45. 1998. “Social Dilemmas: The Anatomy of Cooperation.” Annual Review of Sociology $24: 183-214$.

Lawler, Edward J. 1992. “Affective Attachments to Nested Groups: A Choice-Process Theory.” American Sociological Review 57(3):327-36. 
---------. 2001. “An Affect Theory of Social Exchange.” American Journal of Sociology 107(2):

321-52.

---------. 2002. “Micro Social Orders.” Social Psychology Quarterly 65(1):4-17.

---------. 2006. “Exchange, Affect, and Group Relations.” Pp. 177-202 in George C. Homans:

History, Theory, and Method, edited by A. J. Trevino. Boulder, CO: Paradigm Publishers.

Lawler, Edward J. and Shane R. Thye. 1999. “Bringing Emotions into Social Exchange Theory.” Annual Review of Sociology 25:217-44.

---------. 2006. “Social Exchange Theory of Emotions.” Pp. 295-320 in Handbook of the Sociology of Emotions, edited by J. E. Stets and J. H. Turner. New York: Springer.

Lawler, Edward J., Shane R. Thye, and Jeongkoo Yoon. 2000. “Emotion and Group Cohesion in Productive Exchange” American Journal of Sociology 106(3):616-57.

---------. 2006. “Commitment in Structurally Enabled and Induced Exchange Relations.” Social Psychology Quarterly 69(2): 183-200.

Lawler, Edward J. and Jeongkoo Yoon. 1993. "Power and the Emergence of Commitment Behavior in Negotiated Exchange.” American Sociological Review 58(4)465-81. -. 1996. “Commitment in Exchange Relations: Test of a Theory of Relational Cohesion.” American Sociological Review 61(1):89-108.

---------. 1998. “Network Structure and Emotion in Exchange Relations.” American Sociological Review 63(6):871-94.

LeDoux, Joseph E. 1996. The Emotional Brain: The Mysterious Underpinnings of Emotional Life. New York: Simon \& Schuster.

Levi-Strauss, Claude. 1969. The Elementary Structures of Kinship. Boston, MA: Beacon Press. 
Malinowski, Bronislaw. 1922. Argonauts of the Western Pacific: An Account of Native Enterprise and Adventure in the Archipelagoes of Melanesian New Guinea. London, UK: Routledge.

Markovsky, Barry, David Wilier, and Travis Patton. 1988. "Power Relations in Exchange Networks.” American Sociological Review 53(2):220-36.

Mead, George Herbert. 1934. Mind, Self, and Society. Chicago, IL: University of Chicago Press. Mezulis, Amy, Lyn Y. Abramson, Janet S. Hyde, and Benjamin L. Hankin. 2004. “Is There a Universal Positivity Bias in Attributions? A Meta-Analytic Review of Individual, Developmental, and Cultural Differences in the Self-Serving Attributional Bias.” Psychological Bulletin 130(5):711-47.

Molm, Linda D. 1994. “Dependence and Risk: Transforming the Structure of Social Exchange.” Social Psychology Quarterly 57(3): 163-76.

---------. 2003a. “Theoretical Comparisons of Forms of Exchange.” Sociological Theory 21(1): $1-17$.

---------. 2003b. “Power, Trust, and Fairness: Comparisons of Negotiated and Reciprocal Exchange.” Pp. 31-66 in Advances in Group Processes: Power and Status, Vol. 20, edited by S. R. Thye and J. Skvoretz. Oxford, UK: Elsevier.

Molm, Linda D., Jessica L. Collett, and David R. Schaefer. 2006. “Conflict and Fairness in Social Exchange.” Social Forces 84:2331-52.

---------. 2007. “Building Solidarity through Generalized Exchange: A Theory of Reciprocity.” American Journal of Sociology 113(1):205-42. 
Molm, Linda D. and Karen S. Cook. 1995. “Social Exchange and Exchange Networks.” Pp. 20935 in Sociological Perspectives on Social Psychology, edited by K. S. Cook, G. A. Fine, and J. S. House. Boston, MA: Allyn and Bacon.

Molm, Linda D., Gretchen Peterson, and Nobuyuki Takahashi. 1999. "Power in Negotiated and Reciprocal Exchange.” American Sociological Review 64(6): 876-90.

Molm, Linda D., Nobuyuki Takahashi, and Gretchen Peterson. 2000. "Risk and Trust in Social Exchange: An Experimental Test of a Classical Proposition.” American Journal of Sociology 105(5): 1396-1427.

Moody, James and Douglas R. White. 2003. “Structural Cohesion and Embeddedness: A Hierarchical Concept of Social Groups.” American Sociological Review 68(1): 103-27.

Nee, Victor and Paul Ingram. 1998. "Embeddedness and Beyond: Institutions, Exchange, and Social Structure.” Pp. 19-45 in New Institutionalism in Sociology, edited by M. C. Brinton and V Nee. New York: Russell Sage Foundation.

Parsons, Talcott. 1951. The Social System. Glencoe, IL: Free Press.

Pfeffer, Jeffrey. 1981. Power in Organizations. Marshfield, MA: Pitman Publishing.

Prentice, Deborah A., Dale T. Miller, and Jenifer R. Lightdale. 1994. “Asymmetries in Attachments to Groups and to Their Members: Distinguishing Between CommonIdentity and Common-Bond Groups.” Personality and Social Psychology Bulletin 20(5):484-93.

Ridgeway, Cecilia L. and Cathryn Johnson. 1990. "What Is the Relationship between Socioemotional Behavior and Status in Task Groups?” American Journal of Sociology 95(5): 1189-1212. 
Scheff, Thomas J. 1990. Microsociology: Discourse, Emotion and Social Structure. Chicago, IL: University of Chicago Press.

Simmel, Georg. 1964. The Sociology of Georg Simmel. Edited by K. H. W. Wolff. Glencoe, IL: The Free Press.

Skvoretz, John and Michael J. Lovaglia. 1995. “Who Exchanges with Whom: Structural Determinants of Exchange Frequency in Negotiated Exchange Networks.” Social Psychology Quarterly 58(3): 163-77.

Smith-Lovin, Lynn and David R. Heise, eds. 1988. Analyzing Social Interaction: Advances in Affect Control Theory. New York: Gordon and Breach Science Publishers.

Stolte, John and Richard M. Emerson. 1977. "Structural Inequality: Position and Power in Network Structures.” Pp. 117-38 in Behavioral Theory in Sociology, edited by R. L. Hamblin and J. H. Kunkel. New Brunswick, NJ: Transaction Books.

Stolte, John, Gary Alan Fine, and Karen S. Cook. 2001. "Sociological Miniaturism: Seeing the Big through the Small in Social Psychology.” Annual Review of Sociology 27:387-413. Stryker, Sheldon. 1980. Symbolic Interactionism: A Social Structural Version. Menlo Park, CA: Benjamin/Cummings Publisher.

Swedberg, Richard. 2003. Principles of Economic Sociology. Princeton, NJ: Princeton University Press.

Tajfel, Henri and John C. Turner. 1986. “The Social Identity Theory of Intergroup Behavior.” Pp. 7-24 in Psychology of Intergroup Relations, edited by S. Worchel and W. G. Austin. Chicago, IL: Nelson- Hall.

Thibaut, John W. and Harold H. Kelley. 1959. The Social Psychology of Groups. New York: Wiley. 
Thoits, Peggy A. 1989. “The Sociology of Emotions.” Annual Review of Sociology 15:317-42.

Thye, Shane R. 2000a. “A Status Value Theory of Power in Exchange Relations.” American Sociological Review 65:407-32.

---------. 2000b. “Reliability in Experimental Sociology.” Social Forces 78(4): 1277-1309.

Thye, Shane R., Michael J. Lovaglia, and Barry Markovsky. 1997. "Responses to Social Exchange and Social Exclusion in Networks.” Social Forces 75(3): 1031-47.

Thye, Shane R., Jeongkoo Yoon, and Edward J. Lawler. 2002. “The Theory of Relational Cohesion: Review of a Research Program.” Pp 89-102 in Advances in Group Process, Vol. 19, edited by S. R. Thye and E. J. Lawler. Oxford, UK: Elsevier.

Triplett, Jenny and Shane R. Thye. 2007. "Eliciting Cooperation in Generalized Exchange: The Impact of Social Identity and Non-anonymity.” The Annual Meetings of the American Sociological Association, New York, NY.

Turner, Ralph H. 1978. “The Role and the Person.” American Journal of Sociology 84(1): 1-23.

Turner, Jonathan H. 2000. On the Origins of Human Emotions. Stanford, CA: Stanford University Press.

---------. 2002. Face to Face: Toward a Sociological Theory of Interpersonal Behavior. Stanford, CA: Stanford University Press.

Uzzi, Brian and Ryon Lancaster. 2004. "Embeddedness and Price Formation in the Corporate Law Market.” American Sociological Review 69(3):319-44.

Weiner, Bernhard. 1986. An Attributional Theory of Motivation and Emotion. New York: Springer.

Wilier, David. 1999. Network Exchange Theory. Westport, CT: Praeger Publisher. 
Wilier, David and Bo Anderson. 1981. Networks, Exchange and Coercion: The Elementary Theory and Its Applications. New York: Elsevier.

Williamson, Oliver E. 1985. The Economic Institutions of Capitalism: Firms, Markets, Relational Contracting. New York: Free Press.

Yamagishi, Toshio and Karen S. Cook. 1993. “Generalized Exchange and Social Dilemmas.” Social Psychology Quarterly 56(4):235-48.

Yamagishi, Toshio, Karen S. Cook, and Motoki Watabe. 1998. “Uncertainty, Trust, and Commitment Formation in the United States and Japan.” American Journal of Sociology 104(1): 165-94.

Yamagishi, Toshio and Midori Yamagishi. 1994. "Trust and Commitment in the United States and Japan.” Motivation and Emotion 18(2): 129-66.

Yoon, Jeongkoo and Shane R. Thye. 2000. "Supervisor Support in the Work Place: Legitimacy and Positive Affectivity.” Journal of Social Psychology 140(3):295-316.

---------. 2002. “A Dual Process Model of Organizational Commitment.” Work and Occupations 29(1):97-124. 